\title{
Student Choice: Blends of Technology beyond the University to support social interaction and social participation in learning
}

\author{
Martina A. Doolan, Theo Gilbert \\ University of Hertfordshire, United Kingdom, \\ (m.a.doolan@herts.ac.uk, t.1.gilbert@herts.ac.uk)
}

\begin{abstract}
This paper presents an overview of a blended collaborative learning design driven by assessment and feedback. To extend class based activities students were provided with a private group space on the university managed learning environment. They chose to supplement this using technologies beyond those provided by the University to support their social interactions and participate in their learning. Qualitative data analysis of student's reflections provides insights into the students own blends of technology including Skype, What's App, Facebook amongst others and accessed via their hand held mobile devices such as Smartphones and laptops. These were used by the students to connect and collaborate with their peer group to complete the set tasks throughout the module and the final group based assessment.
\end{abstract}

Keywords: Blended Learning, Collaborative Learning, Technology Enhanced Learning, Group Work, Assessment, Social Media, Social Interaction, Social Participation, Student Choice

\section{Introduction}

This is an ongoing study which builds on previous funded work undertaken with final year undergraduate students studying a BSc in Computer Science [6] and postgraduate students studying an MSc in Software Engineering [8]. The research presented in this paper is a subset of the Social Experiences and Emotional Intelligence in Learning (SEaEIL) project which is a collaboration between the Schools of Humanities and Computer Science and funded under the Social Science Arts and Humanities Research Institute multi-disciplinary research grant 2015-16 at the University of Hertfordshire in the United Kingdom. This study took place over two semesters with 240 first year students undertaking the Human Dimensions module as part of a BSc in Computer Science programme of study.

Situated in a blended social learning context students were engaged in collaborative learning [3] to complete set tasks which hereafter, will be named 'mini-projects', in 
small groups [11] from the module outset. The mini-projects were developed and formed part of the two in-class tests and the final module group based assessment. These were intended to act as a vehicle to provide formative assessment or assessment FOR learning opportunities [1]. In these, students obtained immediate feedback on their work on a weekly basis in class, from their tutor and peers, to help progress learning. The aim was to move away from focusing on a mark usually obtained through summative assessment or assessment OF learning [2] which may fail to engage students in learning [9]. The focus of practice in this paper is on bringing students together inter and intra groups, in and out of class, to learn from each other and gain a better grasp of the subject to develop the necessary knowledge and skills to meet the module learning outcomes. This coming together is described as social participation [10] [13] which encourages social constructivism [12] - the co-creation of knowledge essential for learning. Situated learning theory [10] and community of practice theory [13] also purport that social participation is a key component of learning. [5], [7], [8] argues that the social and cultural context of learning is crucial and a central tenet of learning itself. These social construct theories places emphasis explicitly on the fundamental role that social interaction and social participation play in the process of learning, arguing that meaning is constructed and formed through the social experience, dialogic negotiations and situated in the learning context. In this way, knowledge is socially created and skills developed. Embedding learning within social activity, social context and a social culture encourages learning through observations people make of themselves, others and in the learning environment [7], [13]. The learning environment whether online, offline or a blend of both, is viewed as one that is learner-centric and organic; growing and developing collectively with learners over time and sustained by students and tutors sharing knowledge, ideas and artefact [6], [7], [8]. In this study blended learning is defined where "Students actively engage with the technology alongside traditional faceto-face meetings and class contact" [4].

\section{The Assessment and Feedback Design}

The final assignment was undertaken by 240 students studying a module delivered on the first year BSc programme in Computer Science. Students were allocated to a group of between 4 and 6 students within their respective tutorial group, by the module leader at the beginning of the first semester. Students were expected to work with this group throughout the two semesters. This included completing the final end of year assessment and participating in 12 mini-projects delivered weekly from the module outset. Group changes were permitted if students had met the deadline for requesting a change which was in the second semester. All group members were advised they would receive the same mark for the final group based assessed tasks outlined below. Differences between individuals were expected to be made known in the reflective tasks and submitted separately (if required) from the group report. Where differences were brought to the tutor's attention, students were invited to attend a viva. 
The final assessment comprised two individual and two group tasks to be submitted as one group report and worth $40 \%$ of the total module assessment. To successfully perform on this module, students were expected to pass the module overall. There was no examination component, the module was assessed by $100 \%$ coursework. In total there were four assessments. Two in each semester which comprised one individual written piece and two in-class tests and the final penultimate group based assessment. The students were required to produce a report and undertake a group presentation which was assessed at the end of the module in the second semester. To support knowledge and skills acquisition within group's 12 mini-projects were provided from the outset of the module and aligned with the lecture and assessment material. These were designed to be divisible amongst the group, to engage the students and promote the sharing of knowledge, skills and resources. Moreover, to create a sense of ownership and shared responsibility for learning amongst the student groups.

The mini-projects were delivered on a weekly basis intended to drive the students group learning outside of class to be undertaken together during their independent and self-directed study time. In this way, the learning activities were designed to provide students with an opportunity to collaboratively practice and demonstrate learning, understandings and misunderstandings and to take these back into the classroom for discussion. Moreover, this design also encouraged students to ask and seek answers to questions.

Crucially, the mini-projects were designed to elicit evidence of learning and to obtain feedback from the tutor and potentially up to 25 peers in their tutorial group. Feedback was formative and presented a means for the tutor to reinforce the expected standards and to spontaneously adapt teaching and learning practice to meet the student needs. This feedback was formative by means of informing both student and teacher response Students were required to act on the feedback to develop their work further and seek additional feedback as needed. The completed mini-projects were stored within the students allocated private group space on the MLE, ready to feed-forward into the two in class tests in the first semester and the final group based assessment at the end of the second semester.

The mini-projects were not awarded marks as these were deemed to be formative assessment opportunities. Verbal comments were provided by the tutor and the students in the tutorial. Throughout the two semesters of the module, students uploaded their completed mini-projects on a weekly basis to their allocated private group space on the institutional Managed Learning Environment (MLE). This was required and stipulated on the mini-project specifications. In this way, the online group space was intended to act as a shared repository for students and enabled them to easily locate their work to present to their tutor and peers in class. Storing the mini-projects in this way, removed the necessity for each student group to input a storage device during presentations saving valuable class time.

In summary, the first and fourth tasks of the final assessment were individual reflective pieces on the group process which included the completion of the 12 miniprojects, the group based assessment, technologies used and how these supported the 
group work amongst others. Each student was required to complete the reflective statements, guidance was provided by means of referring students to lecture material and their completed mini-projects. Students were expected to demonstrate how they acted upon the feedback provided by tutors and peers throughout the weekly tutorials and to substantiate their claims with evidence. The second task was a group based essay, on a user experience teardown of a game. Students engaged in discourse around key themes related to the game. The final and third task was a group presentation which provided an opportunity for the students to present their conclusions to their peers and at least two tutors, to ensure double blind marking as part of the assessment process.

\section{Students Use of Technologies beyond the University MLE}

Content analysis was undertaken on the students reflections submitted as part of their final assessment and involved a methodical reading of the texts and the supporting evidence in the form of screen shots. Key themes to emerge related to technology type, application and devices used by students. Presentation of these themes is interweaved with the student comments and the authors' discussion of findings. The student comments were chosen as a unit of text; a phrase, a sentence or multiple sentences and presented verbatim to share their experiences using the students own voice, these appear in italics. The numerical data was produced by counting the number of students associated with each technology type, application and device.

234 students used WhatsApp, an instant messaging application to communicate and collaborate throughout the module and especially to support completion of the miniprojects and the final group based assessment. Evidence in the form of screen shots submitted by students clearly demonstrated their engagement in collaborative discussions over WhatsApp regarding their use of Skype and Google Drive. These were technologies commonly used by students, in addition to, WhatsApp, 180 used Skype and 80 used Google Drive to support their learning.

A student commented on the rationale for using these social technologies:

"Maintain communication" [sic] particularly as "everyone in the group does own a smartphone” [sic].

This was the case for the majority of the students with 220 owning more than one mobile phone, of which, 200 were smartphones. Students reported using these handheld devices as a portal to access Skype, WhatsApp, Facebook, Twitter, Google Drive and the University MLE known as StudyNet. A student comments:

"Our mobile phones aided in the use of WhatsApp and also Study Net" [sic].

Some students found WhatsApp to be "a far quicker and more responsive way of communication for when the members and I were away from the university" [sic]. 
Other comments included:

"The chat helped us plan our meetings and plan the work" [sic].

"This increased productivity and friendships as everyone could speak with everyone in the group" [sic].

"For simplicity and because we all use it already" [sic]

This was commonly cited (180), the majority of students chose to use WhatsApp for ease of use and because they were familiar with the application. In their reflections students discussed how they used this to support learning and to connect and maintain friendships. Some deemed their peer group to be friends. Overall, it was used for planning purposes such as to arrange either Skype or Face to Face meetings and to obtain support from their peer group. Screen shots submitted as evidence for the final assessment showed incidences of students jointly problem solving, asking questions and findings answers from peers.

A group of six students in their reflections noted that using WhatsApp enabled their group to divide into pairs to complete tasks.

"Getting into pairs to complete tasks allowed our shyer individuals significantly more ability to complete tasks and make sure their ideas were heard” [sic]

This was especially important to this group given they discussed having a number of talkative group members. They described how getting into pairs and communicating over WhatsApp helped to reduce overtalkative members propensity to take over communication in the group, to allow others to be heard which created a more inclusive group.

Evidence by means of screen shots included in their reflections clearly show this group of six members using WhatsApp to help each other, and through this social participation were seen to be co-creating knowledge. Furthermore, identities seemed to shift as students became tutors teaching one another.

This student group discussed how sharing ideas strengthened the bond between them and helped develop confidence. They felt encouraged by their peers to share further. It was deemed important to support each other.

For another group of six members WhatsApp was replaced with Kikchat an instant messenger application for mobile devices as this was deemed by this group to be;

"More effective considering Kikchat has features of identification through a username rather than phone number" [sic].

This student group noted this was important to them, as they could use a common password using the group identification number, which they shared amongst the group 
members and they reported accessibility was easy through their mobile phones. The group found this application useful as it was easy to share images and sketches of work undertaken, as well as to send and receive messages.

Additionally, the majority of students (180) used DropBox to share files. Some reasons given include:

"Dropbox to synchronise certain files to where each team member could view and edit them at ease" [sic].

"Dropbox can also restore files that were deleted or discarded by mistake" [sic].

"It also has a feature that indicates the user in case the file is already being modified by somebody else" [sic].

"The decision to get everyone to download Dropbox so files could be synchronised and shared on-demand and over the cloud" [sic].

Skype was used by half the students (120) to communicate whilst working on the mini-projects and the assessed tasks. Evidence provided by means of screen shots clearly demonstrate how groups multi-tasked. For example working between Skype and a Word document. A student comments:

"We also used Skype for those late night and early morning sessions for discussing ideas and inputting into Word at the same time" [sic].

Team Viewer was used by half of the students (120). These students found it useful to be able to view team member's computer screens remotely to share ideas and support each other. A student comments

"to go onto the computer screen of another team members through remote control and help them without being next to them" [sic].

Facebook was used by half the students (120) to carry out discussions in real time, share files and images including photos, especially deemed to be useful by the students when putting together their evidence for the final assessment. Two student comments illustrate this:

"Anyone is struggling we can also send them a video chat using this social platform and show them what is meant by evidence to include in the report" [sic].

"Those who wanted to ask each other about the assessment whilst browsing on Facebook, could now do so through its messenger service" [sic].

Twitter was used by two groups of students (12). 
It appears text and phone calls were used sparingly rather the majority of students used social media technologies to collaborate. Student's comments on this include:

"We used normal text messaging in case the individuals couldn't be reached on WhatsApp or Facebook Messenger" [sic].

"General phone calls were hardly ever made as we preferred to have most things finalised over chat, where it could be read at any time" [sic].

On using laptops a student comments:

"Laptops were used in making communication work. It was used in checking through Study Net" [sic].

"It was used to surf through Study Net, checking online libraries as well as our group created on Study Net" [sic].

Regarding the institutional MLE, the group spaces provided by the module lead to support mini-project completion and the final assessment were used by the majority of students (200) to store their mini-projects. This was not a surprise given they were required to use this as stipulated by the tutor on the mini-project specifications. Other uses of the MLE included the blog (18) and discussion forum (36) features provided within the group space. Some students (24) used the discussion facility within the group space to organize meetings as per the student comment below. Students predominately accessed the MLE using their hand-held devices, mobile phones and laptops.

"Study Net was also used as means for communication. Time slot for our Group meeting sessions are posted on Study Net.

However, its use was minimal in comparison to the social technologies the students chose to use beyond the university. It seems the majority of students preferred WhatsApp rather than the University MLE, a student comments

"to ease the sharing of ideas, we decided to open a group Chat on WhatsApp to enable us share ideas besides just at our group meetings. WhatsApp was chosen because it is commonly used among students and it is quicker to access than Study Net" [sic].

\section{Conclusion}

This paper provided an insight into a formative assessment design as a driver to encourage social interaction and social participation between students using a collaborative learning approach to support completion of the 12 mini-projects throughout the module and the final group based assessment. Private group spaces housed on the MLE were provided and intended to support students' group work. The majority of students chose to use a blend of technologies and applications familiar to 
them which were beyond those provided by the University. These enabled easy access to their peer group and resources.

Acknowledgments. The students and tutors who participated on the module and sincere gratitude to the Social Science Arts and Humanities Research Institute at the University of Hertfordshire in the UK for funding this project.

\section{References}

1. Black, P., \& Wiliam, D. Developing a theory of formative assessment. In Gardner J. (eds.) Assessment and learning 2006. pp. 81-100. Sage, London (2006)

2. William D. \& P. Black (1996) Meanings and Consequences: a basis for distinguishing formative and summative functions of assessment? British Educational Research Journal, 22(5) 537-548.

3. Dillenbourg, P. What do you mean by collaborative learning? In: Dillenbourg, P. (eds.) Collaborative Learning: Cognitive and Computational Approaches. Advances in Learning and Instruction Series (1999). General Learning Press, New York (1999)

4. Doolan, M. A. Effective Strategies for Building a Learning Community Online using Wiki. In: 1st Annual Blended Learning Conference pp. 51-63 University of Hertfordshire United Kingdom (2006)

5. Doolan, M. A. Developing Pedagogy: The Role of the Tutor in Enabling Student Learning through the Use of a Wiki. In: Wankel, C. (eds.) Educating Educators in Social Media 2010. pp. 189-206 Emerald Group Publishing Ltd. Bingley (2011)

6. Doolan, M. \& Morris, P. Developing principles in practice: a dialogue in assessment and feedback In: 5th International Blended Learning Conference pp. 38-45 University of Hertfordshire United Kingdom (2010)

7. Doolan, M. A. A Pedagogical Framework For Collaborative Learning in a Social Blended E Learning Context in Wankel, C \& Blessenger, P. (eds.) Increasing Student Engagement and Retention in e-Learning Environments: Web 2.0 and Blended Learning Technologies 2013. pp. 261-286 Emerald Group Publishing Ltd Bingley (2013)

8. Doolan, M. A. Enhancing the postgraduate experience of assessment and feedback in a learning community. In: 8th International Conference on E-Learning pp136-142 Cape Peninsula University of Technology: Cape Town, South Africa (2013)

9. Ecclestone K. From testing to productive student learning: implementing formative assessment in Confucian-heritage Settings. Assessment in Education: Principles, Policy \& Practice, 19(2) 255-276 (2012)

10. Lave, J. \& Wenger, E. Situated Learning Legitimate Peripheral Participation. Cambridge University Press Cambridge (1991)

11. Lewin, K. Field Theory in Social Science. Harper and Row New York (1951)

12. Vygotsky, L.S. Mind in Society. Cambridge MA: Harvard University Press (1978)

13.Wenger, E. Communities of Practice: Learning, Meaning and Identity. Cambridge University Press Cambridge (1998) 